\title{
SiOx Top Layer on DLC Films for Atomic Oxygen and Ozone Corrosion Protection in Aerospace Applications
}

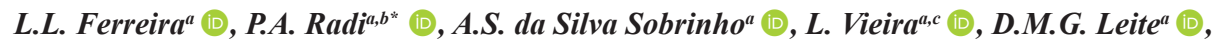 \\ A.A.C. Recco ${ }^{e}$ (D), D.A.P. Reis ${ }^{b}$ (1), M. Massi ${ }^{a, d}$ (]) \\ aInstituto Tecnológico de Aeronáutica, Laboratório de Plasmas e Processos, São José dos Campos, SP, Brasil \\ ${ }^{b}$ Universidade Federal de São Paulo (UNIFESP), Programa de Pós-Graduação em Engenharia e \\ Ciência dos Materiais, São José dos Campos, SP, Brasil \\ 'Universidade do Vale do Paraíba (UNIVAP/IP\&D), São José dos Campos, SP, Brasil \\ ${ }^{d}$ Universidade Presbiteriana Mackenzie, Programa de Pós-Graduação em Engenharia de Materiais e \\ Nanotecnologia (PPGEMN), São Paulo, SP, Brasil \\ eUniversidade do Estado de Santa Catarina, Laboratório de Física dos Plasmas, 89219-710, Joinville, \\ SC, Brasil
}

Received: November 10, 2020; Revised: April 04, 2021; Accepted: April 06, 2021

Every year, billions of dollars are invested in research and development for space applications, including new systems, new technologies, and new materials. DLC (Diamond-Like Carbon) is a promising material for use in these applications, but its use faces a technological barrier, since it is severely etched by atomic oxygen and ozone. In this study, SiOx-DLC thin films were deposited as a top layer of diamond-like carbon (DLC) films on Ti-6Al-4V substrates to increase resistance against corrosion by atomic oxygen and ozone as well as meet the requirements for use in Low Earth Orbit (LEO) satellites. The corrosion resistance of the films was evaluated using oxygen plasma, and the tribological and mechanical properties were investigated. The SiOx-DLC top layer reduced the corrosion rate two orders of magnitude and increased the critical load from $16.2 \pm 1.5 \mathrm{~N}$ to $18.4 \pm 0.4 \mathrm{~N}$.

Keywords: $D L C$, SiOx-DLC, tribology, atomic oxygen, ozone, corrosion protection.

\section{Introduction}

The main space agencies of the world invest billions of dollars every year in research and development for important projects, such as the building of the international space station, satellite launch vehicles, and many kinds of satellites ${ }^{1,2}$. Among the areas involved in these projects, surface engineering plays an important role, due to the severe conditions that these devices are subjected ${ }^{3-5}$. The tribology for space applications has been studied since the1940s, and in 1996 Donnet published an overview on recent tribological studies performed on MoS2 and DLC in ultra-high vacuum (UHV) ${ }^{6,7}$. Diamond-like carbon (DLC) thin films have been extensively studied for this purpose, due to their appropriate tribological characteristics, such as a stable and low wear rate ${ }^{8}$. However, the use of DLC films for these aerospace applications faces a technical barrier, since they are severely etched by atomic oxygen present in the low orbit atmosphere (200 to $700 \mathrm{~km}$ ), resulting in a significant lifetime reduction ${ }^{9-11}$. Methods to increase the lifetime of the DLC film include incorporation of dielectric and metallic nanoparticles ${ }^{12,13}$. Marciano et al. ${ }^{14}$, for example, showed that DLC films have higher wear resistance against oxygen attack when silver nanoparticles are incorporated into the film. In Low Earth Orbit (LEO), atomic oxygen

*e-mail: marcos.massi@mackenzie.br with energy of $4.2-45 \mathrm{eV}$ can degrade covalent bonds and molecular chains of polymeric materials ${ }^{15}$ and DLC films ${ }^{16}$. Reactive ion etching (RIE) also called "chemical sputtering"17 can be used to test the corrosion resistance of thin films, simulating $\mathrm{LEO}^{14,18}$.

In this work, silicon oxide ( $\mathrm{SiOx}$ ) was incorporated into the DLC during the last minutes of deposition to produce a corrosion resistant top layer (SiOx- DLC), maintaining its desirable mechanical and tribological properties. The influence of this top layer on the tribological properties of the DLC film was investigated. The mechanical, structural properties, and corrosion resistance of the films were also evaluated.

\section{Experimental Procedure}

DLC and SiOx-DLC films were grown on Ti-6Al-4V substrates by a pulsed DC PECVD (Plasma Enhanced Chemical Vapor Deposition) discharge following the sequence presented in Table 1. A silicon interlayer was deposited to improve the adherence of the film, and the mixed interlayer improved the cohesion between interlayer and DLC film. The

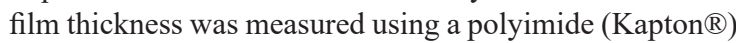
tape as a physical mask. The silicon interlayer thickness was about $228 \mathrm{~nm}$, the DLC film was around $1.5 \mu \mathrm{m}$ and $800 \mathrm{~nm}$ for SiOx-DLC, the final thickness considering SiOx-DLC film was around $2.5 \mu \mathrm{m}$. The $\mathrm{SiOx}$ top layer was deposited 
Table 1. Deposition parameters of the DLC and SiOx-DLC films.

\begin{tabular}{|c|c|c|c|c|c|}
\hline Film & Steps & Plasma Environment & Pressure (Torr) & Temperature $\left({ }^{\circ} \mathrm{C}\right)$ & Time $(\min )$ \\
\hline \multirow{6}{*}{ DLC } & Cleaning & Argon & $10^{-1}$ & 550 & 40 \\
\hline & \multirow{2}{*}{ Interlayer } & HDMSO* & \multirow{2}{*}{$10^{-1}$} & \multirow{2}{*}{500} & \multirow{2}{*}{30} \\
\hline & & Argon & & & \\
\hline & \multirow{2}{*}{ Mixed layer } & Hexane & \multirow{2}{*}{$10^{-2}$} & \multirow{2}{*}{230} & \multirow{2}{*}{5} \\
\hline & & HDMSO & & & \\
\hline & DLC & Hexane & $10^{-2}$ & 211 & 90 \\
\hline \multirow{7}{*}{ SiOx-DLC } & Cleaning & Argon & $10^{-1}$ & 550 & 40 \\
\hline & \multirow{2}{*}{ Interlayer } & HDMSO & \multirow{2}{*}{$10^{-1}$} & \multirow{2}{*}{500} & \multirow{2}{*}{30} \\
\hline & & Argon & & & \\
\hline & \multirow{2}{*}{ Mixed layer } & Hexane & \multirow{2}{*}{$10^{-2}$} & \multirow{2}{*}{230} & \multirow{2}{*}{5} \\
\hline & & HDMSO & & & \\
\hline & DLC & Hexane & $10^{-2}$ & 211 & 60 \\
\hline & $\mathrm{SiOx}-\mathrm{DLC}$ & HDMSO & $10^{-1}$ & 108 & 30 \\
\hline
\end{tabular}

"HDMSO: Hexamethyldisiloxane

to increase the corrosion resistance of the films. The $\mathrm{SiOx}$ provides interaction of $\mathrm{Si}$ atoms with oxygen forming a passivated layer.

To analyze the corrosion resistance of the films, they were submitted to corrosion by oxygen plasma in a reactive ion etching (RIE) reactor. The plasma was produced by an RF signal (13.5 MHz) applied between the external structure of the chamber (grounded) and an electrode located $50 \mathrm{~mm}$ below its upper cover. The lower electrode temperature was kept at $23{ }^{\circ} \mathrm{C}$ by using a water cooling system. The corrosion tests were performed under $12 \mathrm{sccm}$ of $99.999 \%$ pure oxygen gas flow, pressure of $10^{-3}$ Torr, RF power of $10 \mathrm{~W}$, and $\mathrm{V}_{\text {bias }}$ of $-179 \mathrm{~V}$. This $\mathrm{V}_{\text {bias }}$ was used because it was the energy required to obtain measurable corrosion rate on SiOx-DLC films. The DLC films were corroded for $22 \mathrm{~min}$ and the SiOx-DLC for $258 \mathrm{~min}$ to enable observation of measurable corrosion and calculation of the corrosion rate.

During deposition and corrosion processes, part of the sample was covered with a mechanical mask to produce a step between the substrate and the film and between the corroded and non-corroded regions. These steps were analyzed by using an optical microscope (Veeco - Wyko NT 1100), and the corrosion rates were then calculated.

The film adhesion was evaluated by using scratching test performed on a UMT (Universal Mechanical Tester) using a $120^{\circ}$ Rockwell-C Diamond tip according to ASTM $\mathrm{C} 1624^{19}$. The normal load was applied from $0.2 \mathrm{~N}$ to $30 \mathrm{~N}$ in a length of $10 \mathrm{~mm}$, at $0.1 \mathrm{~mm} \cdot \mathrm{s}^{-1}$ sliding speed. The tests were performed in triplicate, and the critical load $(\mathrm{N})$ was considered the load necessary to remove the film and expose the substrate ${ }^{20,21}$.

EDS (Energy-dispersive X-ray spectroscopy) was used to determine the chemical concentration of carbon, oxygen, and silicon in the corroded and non-corroded films. The structural properties of the films were analyzed by Raman scattering spectroscopy, using a Renishaw 2000 system with an $\operatorname{Ar}$ laser $(\lambda=514 \mathrm{~nm})^{22}$. The equipment was calibrated with a diamond sample that presents a peak at $1332 \mathrm{~cm}^{-1}$. Through the slope of the background photoluminescence of the Raman spectra, the percentage of hydrogen content in the DLC films was estimated. The DLC films for space application can have high values of hydrogen content to work as solid tape as a physical mask lubricant in deep space where there is no water interactions ${ }^{23}$. The spectra were decomposed into two Gaussian lines to analyze its shape and $\mathrm{I}_{\mathrm{D}} / \mathrm{I}_{\mathrm{G}}$ ratio.

Hardness $(\mathrm{H})$ and Young's modulus (E) of the films were measured using a Berkovich nanoindenter in a nanomicro tribometer of a multifunctional tribometer universal mechanical tester (UMT) from BRUKER, applying a load of $10 \mathrm{mN}^{24,25}$. To eliminate the influence of the hardness of the substrate, the penetration depths were less than $10 \%$ of the film thickness. The average hardness of each sample was obtained through 12 indentations.

\section{Results and Discussion}

The scratching test was used for both DLC and SiOxDLC films, and the representative results can be observed in Figure 1. The critical load was defined as $\mathrm{LC}_{1}$ for the load necessary to crack the film, evidenced by the acoustic emission and image observation, and $\mathrm{LC}_{2}$ as the load to damage the film and expose the substrate, evidenced by the increased the friction coefficient $\left(\mathrm{LC}_{1} 11.2 \pm 1.8 \mathrm{~N}\right.$ for DLC $14.5 \pm 2.0 \mathrm{~N}$ for $\mathrm{SiOx}-\mathrm{DLC})$. The mean critical loads were $19.9 \pm 0.8 \mathrm{~N}$ and $18.4 \pm 0.4 \mathrm{~N}$ for DLC and SiOx-DLC films, respectively, indicating that the films were very adherent and that the $\mathrm{SiOx}$ did not interfere with the film scratch resistance ${ }^{26,27}$. Lateral cracks could be observed in Lc1 at the border of the scratch track, and chipping failure could be observed in the track on $\mathrm{LC}_{2}$, which is the same behavior observed by Nass et al. on films deposited by $\mathrm{HDMSO}^{28}$. For $\mathrm{SiOx}-\mathrm{DLC}$, the first cracks occurred in a higher load than DLC films but was accompanied by total failure.

The corrosion rate (by oxygen plasma) and the surface roughness $(\mathrm{Ra})$, before and after corrosion test, were evaluated using an optical profiler. All the presented values were obtained by averaging five measurements. The results summarized in Table 2 show that the corrosion processes tend to decrease the film roughness in both cases (pure DLC and SiOx-DLC samples), probably caused by the plasma etching process.

Figures $2 \mathrm{a}$ and $2 \mathrm{~b}$ present the images obtained from the step produced by the oxygen plasma on DLC and SiOx-DLC films, respectively. A decrease in the roughness of the films 
Table 2. Corrosion rate and surface roughness (Ra) of the films.

\begin{tabular}{ccc}
\hline Sample & Corrosion Rate $(\AA / \mathrm{min})$ & Surface Roughness Ra $(\mathrm{nm})$ \\
\hline DLC & \multirow{2}{*}{$434 \pm 26$} & $100 \pm 6$ (non-corroded) \\
\cline { 2 - 3 } SiOx-DLC & $2.4 \pm 0.6$ & $92 \pm 5$ (corroded) \\
\cline { 2 - 2 } & & $69 \pm 6$ (non-corroded) \\
\hline
\end{tabular}

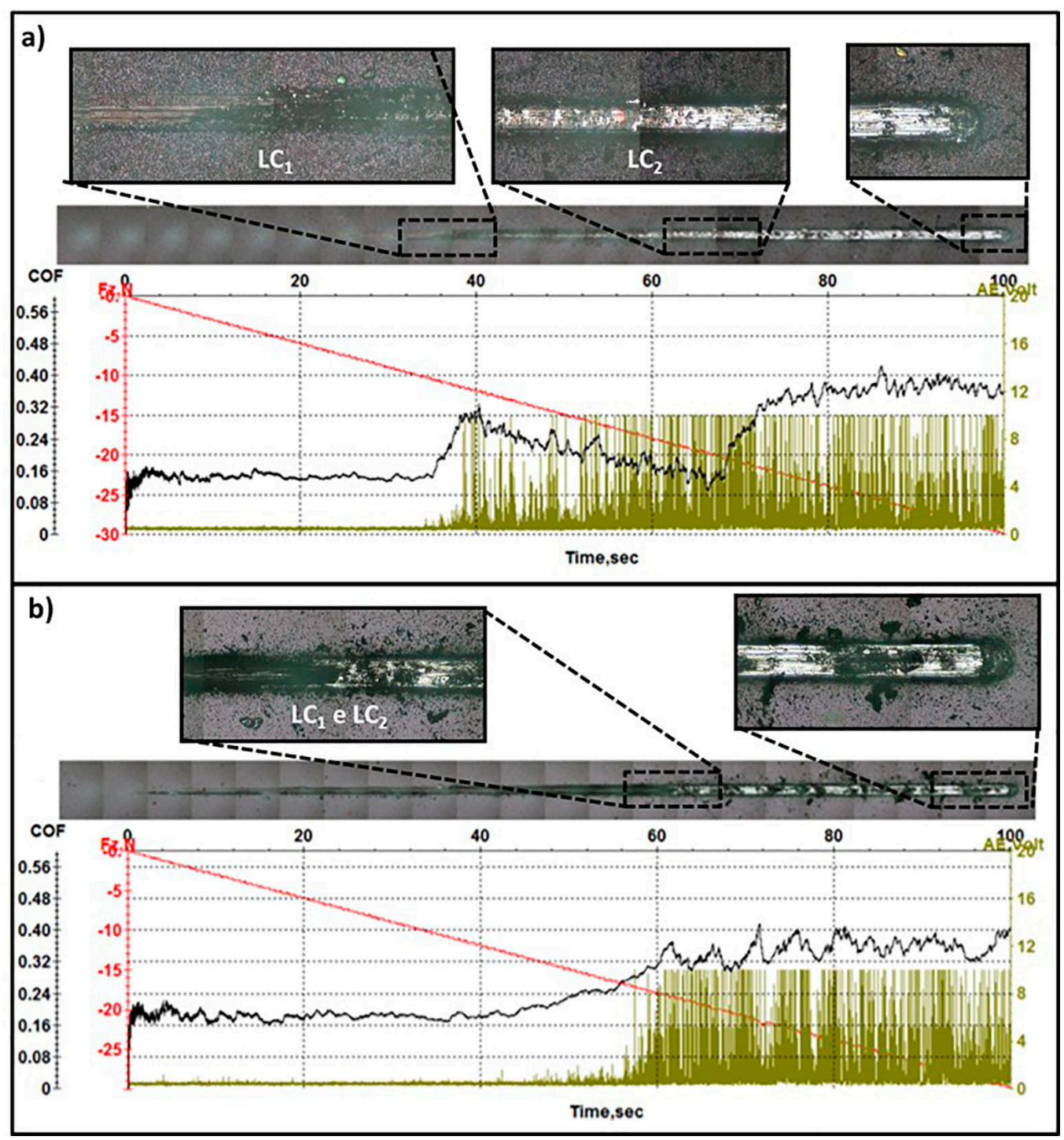

Figure 1. Track images obtained by scratch test with a highlight on the critical load positions on the track image. Scratch test results for (a) DLC and (b) SiOx-DLC show friction coefficient (COF), normal load (FZ), and acoustic emission (AE) as a function of time.

for both cases (pure DLC and SiOx-DLC samples) can also be observed and confirmed by the Ra values in Table 2 .

The corrosion rate of SiOx-DLC films was two orders of magnitude lower than that observed for DLC film. The low corrosion rate obtained for $\mathrm{SiOx}-\mathrm{DLC}(2.4 \AA / \mathrm{min})$ in the oxygen plasma used in this work indicates that this material is a strong candidate for corrosion protective film on LEO environments ${ }^{29}$. Atomic oxygen reacts with silicon forming $\mathrm{SiOx}$ with $1<\mathrm{x}<6$, as demonstrated by Nicolae Tomozeiu ${ }^{30}$.

Tagawa et al. performed studies on ozone corrosion of $\mathrm{MoS}_{2}$ and DLC films ${ }^{16}$. They demonstrated that, after oxygen corrosion, the DLC films present a high friction coefficient (0.38), but after a friction period, the friction return to low values $(0.05)$. They concluded that the protection of DLC film is mandatory for LEO space application. In this study, was demonstrated that SiOx-DLC films are able to protect DLC films from corrosion using values of energy 36 times higher than the value in space. The DLC was corroded for $22 \mathrm{~min}$ and the SiOx-DLC for $258 \mathrm{~min}$, in order to observe measurable corrosion rate.

Table 3 presents the chemical concentrations of corroded and non-corroded DLC and SiOx-DLC films obtained by 


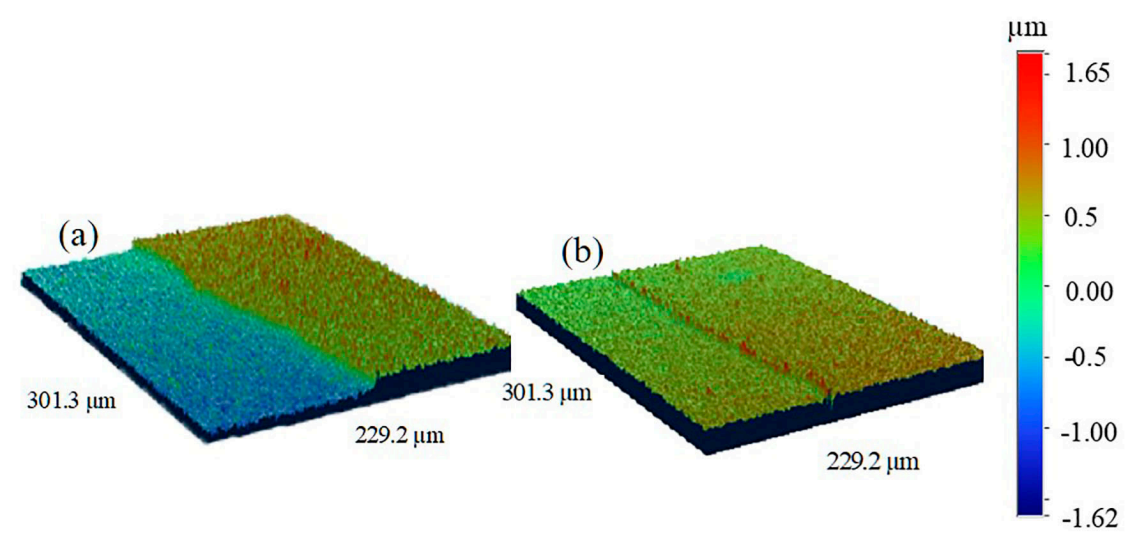

Figure 2. Optical microscopy image of the step observed for (a) DLC and (b) SiOx-DLC after 22 and 258 minutes of exposition to oxygen plasma, respectively.

Table 3. Chemical concentrations obtained by EDS from the surface of corroded and non-corroded DLC and SiOx-DLC films.

\begin{tabular}{ccccc}
\hline Chemical elements & DLC (non-corroded) & DLC (corroded) & $\begin{array}{c}\text { SiOx-DLC } \\
\text { (non- corroded) }\end{array}$ & SiOx-DLC (corroded) \\
\hline $\mathrm{C}$ & $97.5 \pm 0.2$ & $89.6 \pm 0.7$ & $27.6 \pm 0.3$ & $26.0 \pm 0.4$ \\
\hline $\mathrm{O}$ & $0.9 \pm 0.2$ & $2.2 \pm 0.5$ & $30.2 \pm 0.3$ & $31.7 \pm 0.4$ \\
\hline $\mathrm{Si}$ & $1.1 \pm 0.1$ & $7.3 \pm 0.2$ & $41.4 \pm 0.1$ & $41.5 \pm 0.1$ \\
\hline $\mathrm{Ti}$ & $0.4 \pm 0.0$ & $0.7 \pm 0.0$ & $0.7 \pm 0.1$ & $0.7 \pm 0.0$ \\
\hline $\mathrm{Al}$ & $0.1 \pm 0.1$ & $0.2 \pm 0.0$ & $0.1 \pm 0.0$ & $0.1 \pm 0.0$ \\
\hline $\mathrm{V}$ & $0.0 \pm 0.0$ & $0.0 \pm 0.0$ & $0.0 \pm 0.1$ & $0.0 \pm 0.0$ \\
\hline
\end{tabular}

Table 4. Properties of DLC film obtained by Raman spectroscopy and hardness measurements.

\begin{tabular}{lccccc}
\hline \multicolumn{1}{c}{ Samples } & $\mathrm{H}(\%)$ & $\mathrm{I}_{\mathrm{D}} / \mathrm{I}_{\mathrm{G}}$ & $\mathrm{H}(\mathrm{GPa})$ & $\mathrm{E}(\mathrm{GPa})$ & $\mathrm{H} / \mathrm{E}\left(\mathrm{x} 10^{-2}\right)$ \\
\hline DLC non-corroded & $33.8 \pm 0.9$ & $0.40 \pm 0.05$ & $9.1 \pm 2.8$ & $79.0 \pm 13.0$ & $11.5 \pm 1.6$ \\
\hline DLC corroded & $32.7 \pm 1.1$ & $0.47 \pm 0.04$ & $6.3 \pm 1.8$ & $66.0 \pm 13.0$ & $9.5 \pm 0.8$ \\
\hline SiOx-DLC non-corroded & $37.0 \pm 0.5$ & $0.36 \pm 0.04$ & $2.3 \pm 0.2$ & $25.5 \pm 1.8$ & $9.0 \pm 0.1$ \\
\hline SiOx-DLC corroded & $36.4 \pm 0.6$ & $0.41 \pm 0.02$ & $2.2 \pm 0.1$ & $27.2 \pm 1.3$ & $8.0 \pm 0.1$ \\
\hline
\end{tabular}

EDS. The chemical composition of SiOx-DLC surface remained unaffected by the corrosion process used in this work. For pure DLC film, however, the $\mathrm{O}$ and Si concentration significantly increased, and the $\mathrm{C}$ concentration decreased after the corrosion process, indicating that the electron beam was deep enough to reach the Si interlayer produced by the HMDSO plasma (step 2 of the deposition process). The presence of $\mathrm{Ti}, \mathrm{Al}$, and $\mathrm{V}$ in the film is very low and originated from the substrate.

The Raman spectra of corroded and non-corroded DLC and SiOx-DLC films are displayed in Figure 3. Only the typical DLC Raman features are observed (D and G bands) ${ }^{31-33}$. The percentage of hydrogen in the films was calculated from the slope of the background photoluminescence showed in plots of Figure 3. This methodology was successfully used for pure DLC films and is described in detail by Casiraghi et al. ${ }^{34}$. $\mathrm{I}_{\mathrm{D}} / \mathrm{I}_{\mathrm{G}}$ ratio was obtained from the Raman spectra in Figure 3.

The hydrogen content of the films before and after corrosion were calculated by using the equation developed by Casiraghi et al. that uses the ratio between the slope of the Raman spectra (m), between 1050 and $1800 \mathrm{~cm}$, and the intensity of the $\mathrm{G}$ peak, $\mathrm{m} / \mathrm{I}(\mathrm{G}){ }^{35}$.

Table 4 summarizes the Raman and hardness results for DLC and SiOx-DLC before and after corrosion tests.

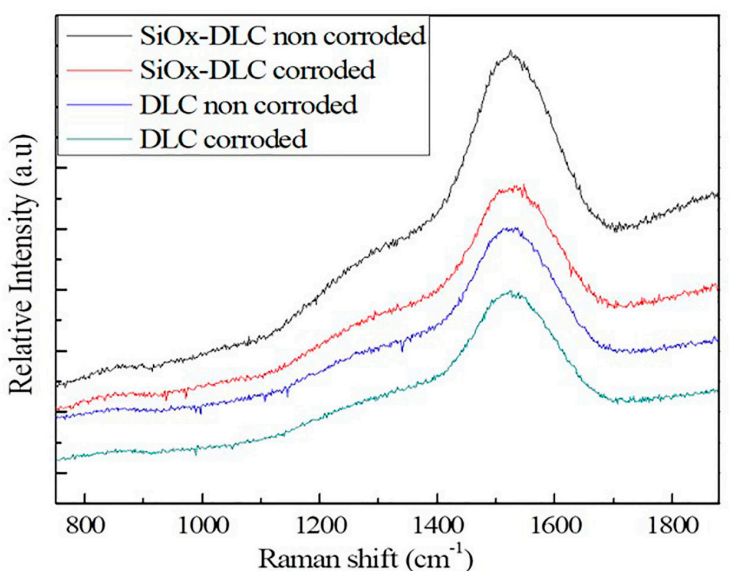

Figure 3. Raman spectra from corroded and non-corroded DLC and $\mathrm{SiOx}-\mathrm{DLC}$ films.

SiOx-DLC films present lower values of $\mathrm{I}_{\mathrm{D}} / \mathrm{I}_{\mathrm{G}}$ than pure DLC, for both corroded and non-corroded films, which agrees with the higher hydrogen concentration obtained for these samples (Table 4). The results showed a drastic reduction in both hardness and Young's modulus of the 
SiOx-DLC films when compared with DLC film ${ }^{36}$. This behavior was expected, since $\mathrm{SiOx}$ material formed in the top layer SiOx-DLC presents lower $\mathrm{H}$ and $\mathrm{E}$ values than the pure DLC. The values of hardness and Young's modulus of SiOx-DLC films reported in the literature are $\sim 3.6 \mathrm{GPa}^{37}$ and $20.0 \mathrm{GPa}^{38}$, respectively. For DLC, literature states that $8.6 \mathrm{GPa}$ and $70 \mathrm{GPa}$ are typical values of hardness and Young's modulus, respectively ${ }^{39}$.

\section{Conclusion}

In this work, we investigated the properties of SiOx-DLC deposited as a top layer on a DLC film grown by DC-pulsed PECVD technique. Both SiOx-DLC and pure DLC films exhibited good adherence to the Ti-6Al-4V substrates. $\mathrm{SiOx}-\mathrm{DLC}$ films presented significant decrease in hardness and Young modulus of about $70 \%$ compared to pure DLC. The SiOx-DLC films reduced the DLC corrosion rate by two orders of magnitude. These results demonstrate that a SiOx-DLC top layer is a good choice to resist oxygen corrosion and could be used as a protective coating for spacecraft materials exposed to LEO orbit.

\section{Acknowledgments}

The authors thank CNPq (grant number 560054/2010-6) and CAPES (grant numbers 88882.161953/2017-01, $88882.306590 / 2018-01)$ for financial support. They also acknowledge resources and support from the laboratory LABAS-INPE for characterization of the samples.

\section{References}

1. Devezas T, de Melo FCL, Gregori ML, Salgado MCV, Ribeiro JR, Devezas CBC. The struggle for space: past and future of the space race. Technol Forecast Soc Change. 2012;79(5):963-85. http://dx.doi.org/10.1016/j.techfore.2011.12.006.

2. Schrogl KU, Hays PL, Robinson J, Moura D, Giannopapa C. Handbook of space security. USA: Springer International Publishing; 2015.

3. Gao X, Hu M, Sun J, Fu Y, Yang J, Weng L, et al. Changes in the structure and tribological property of $\mathrm{Ag}$ film by LEO space environment exposure. Appl Surf Sci. 2014;320:466-70. http://dx.doi.org/10.1016/j.apsusc.2014.08.197.

4. Dunn BD. Materials and processes for spacecraft and high reliability applications. MRS Bull. 2017;42(04):324. http:// dx.doi.org/10.1557/mrs.2017.79.

5. Tagawa M, Kishida K, Yokota K, Matsumoto K, Yoshigoe A, Teraoka Y, et al. Survivability of Silicon-Doped Diamond-Like Carbon Films in Energetic Atomic/Molecular Oxygen Beam Environments. In: Kleiman J, Tagawa M, Kimoto Y, editors. Protection of Materials and Structures From the Space Environment. Astrophysics and Space Science Proceedings, vol 32. Berlin, Heidelberg: Springer; 2013. https://doi.org/10.1007/978-3-64230229-9_51.

6. Santos LV, Trava-Airoldi VJ, Corat EJ, Nogueira J, Leite NF. DLC cold welding prevention films on a Ti6Al4V alloy for space applications. Surf Coat Tech. 2006;200(8):2587-93. http://dx.doi.org/10.1016/j.surfcoat.2005.08.151.

7. Donnet C. Advanced solid lubricant coatings for high vacuum environments. Surf. Coatings Technol. 1996;80(1-2):151-6. http://dx.doi.org/10.1016/0257-8972(95)02702-5.

8. Kanda K, Fukuda K, Kidena K, Imai R, Niibe M, Fujimoto $\mathrm{S}$, et al. Hyperthermal atomic oxygen beam irradiation effect on the Ti-containing DLC film. Diam. Relat. Mater. 2014;41:49-52.
9. Hooshangi Z, Hossein Feghhi SA, Saeedzadeh R. The effects of low earth orbit atomic oxygen on the properties of Polytetrafluoroethylene. Acta Astronaut. 2016;119:233-40. http://dx.doi.org/10.1016/j.actaastro.2015.11.031.

10. Gao X-m, Fu Y-1, Hu M, Sun J-y, Yang J, Liu W-m, et al. LEO space environment exposure resistant behavior of Ag-Cu films. Surf Coatings Technol. 2015;303-8.

11. Chen L, Li Z, Lee C-H, Jiahong W. Unified model for lowEarth-orbital atomic-oxygen and atomic-oxygen/ultraviolet induced erosion of polymeric materials. Aerosp Sci Technol. 2016;53:194-206. http://dx.doi.org/10.1016/j.ast.2016.03.016.

12. Zhang CZ, Tang Y, Li YS, Yang Q. Adhesion enhancement of diamond-like carbon thin films on Ti alloys by incorporation of nanodiamond particles. Thin Solid Films. 2013;528:111-5. https://doi.org/10.1016/j.tsf.2012.05.094.

13. Oliveira CAGS, Stein MF, Saito E, Zanin H, Vieira LS, Raniero $\mathrm{L}$, et al. Effect of gold oxide incorporation on electrochemical corrosion resistance of diamond-like carbon. Diam Relat Mater. 2015;53:40-4.

14. Marciano FR, Bonetti LF, Pessoa RS, Marcuzzo JS, Massi M, Santos LV, et al. The improvement of DLC film lifetime using silver nanoparticles for use on space devices. Diam Relat Mater. 2008;17(7-10):1674-9.

15. Wang X, Li Y, Qian Y, Qi H, Li J, Sun J. Mechanically robust atomic oxygen-resistant coatings capable of autonomously healing damage in low earth orbit space environment. Adv Mater. 2018;30(36):1. http://dx.doi.org/10.1002/adma.201803854. PMid:30022535.

16. Tagawa M, Yokota K, Matsumoto K, Suzuki M, Teraoka Y, Kitamura A, et al. Space environmental effects on MoS2 and diamond-like carbon lubricating films: atomic oxygen-induced erosion and its effect on tribological properties. Surf Coatings Technol. 2007;202(4-7):1003-10.

17. Mattox DM. The foundations of vacuum coating technology. USA: William Andrew; 2013.

18. Banks BA, de Groh KK, Miller SK. Low Earth orbital atomic oxygen interactions with materials. Mater Res. 2004;851:NN8.1. http://dx.doi.org/10.1557/PROC-851-NN8.1.

19. ASTM International. ASTM C1624-05 (2015): Standard Test Method for Adhesion Strength and Mechanical Failure Modes of Ceramic Coatings by Quantitative Single Point Scratch Testing. West Conshohocken: ASTM International.

20. Burnett PJ, Rickerby DS. The relationship between hardness and scratch adhession. Thin Solid Films. 1987;154(1-2):403-16. http://dx.doi.org/10.1016/0040-6090(87)90382-8.

21. Burnett PJ, Rickerby DS. The scratch adhesion test: an elasticplastic indentation analysis. Thin Solid Films. 1988;157(2):23354. http://dx.doi.org/10.1016/0040-6090(88)90006-5.

22. Vieira AA, Manfroi LA, Lobo LZ, Santos TB, Silva SA, de Vasconcelos G, et al. Tribocorrosion susceptibility and osseointegration studies of silicon-carbon-titanium oxide coatings produced on SS316L by laser cladding. J Bio Tribo Corros. 2021;7:5.

23. Erdemir A. The role of hydrogen in tribological properties of diamond-like carbon films. Surf Coat Tech. 2001;146-147:2927. http://dx.doi.org/10.1016/S0257-8972(01)01417-7.

24. Pharr GM. An improved technique for determining hardness and elastic modulus using load and displacement sensing indentation experiments. J Mater Res. 1992

25. Charitidis CA. Nanomechanical and nanotribological properties of carbon-based thin films: a review. Int $J$ Refract Met Hard Mater. 2010;28(1):51-70. http://dx.doi.org/10.1016/j. ijrmhm.2009.08.003.

26. Rodrigo A, Ichimura H. Analytical correlation of hardness and scratch adhesion for hard films. Surf Coatings Technol. 2001;148(1):8-17. http://dx.doi.org/10.1016/S0257-8972(01)013299. 
27. Rodrigo A, Perillo P, Ichimura H. On the correlation of substrate microhardness with the critical load of scratch adherence for hard coatings. Surf. Coatings Technol. 2000;124(2-3):87-92. http://dx.doi.org/10.1016/S0257-8972(99)00640-4.

28. Nass KCF, Radi PA, Leite DMG, Massi M, da Silva Sobrinho AS, Dutra RCL, et al. Tribomechanical and structural properties of a-SiC:H films deposited using liquid precursors on titanium alloy. Surf Coat Tech. 2015;284:240-6. http://dx.doi.org/10.1016/j. surfcoat.2015.06.080.

29. Batory D, Jedrzejczak A, Kaczorowski W, Kolodziejczyk L, Burnat B. The effect of Si incorporation on the corrosion resistance of a-C:H:SiOx coatings. Diam Relat Mater. 2016;67:1-7.

30. Tomozeiu N. Silicon oxide ( $\mathrm{SiOx}, 0<\mathrm{x}<2$ ): a challenging material for optoelectronics. In: Predeep P, editor. Optoelectronics: materials and techniques. London: InTech; 2011.

31. Song H, Ji L, Li H, Liu X, Zhou H, Liu L, et al. Interface design for a-C:H film with super long wear life in high vacuum environment. Tribol Int. 2016;95:298-305. http://dx.doi. org/10.1016/j.triboint.2015.11.033.

32. Hamdan A, Al Makdessi G, Margot J. Synthesis of amorphous hydrogenated carbon thin films by magnetized radio-frequency discharge in argon-acetylene mixture at very low gas pressure. Thin Solid Films. 2016;599:84-97. http://dx.doi.org/10.1016/j. tsf.2015.12.057.

33. Huang L, Yuan J, Li C, Wang Z, Zhou T, Yin Z. Influence of annealing temperature on thermal stabilities of hydrogenated amorphous carbon on silicon nitride balls. Vacuum. 2016;127:96102. http://dx.doi.org/10.1016/j.vacuum.2016.02.017.

34. Casiraghi C, Ferrari AC, Robertson J. Raman spectroscopy of hydrogenated amorphous carbons. Phys Rev B Condens Matter Mater Phys. 2005;72(8):1. http://dx.doi.org/10.1103/ PhysRevB.72.085401.

35. Casiraghi C, Ferrari C, Robertson J. Raman spectroscopy of hydrogenated amorphous carbons. Phys Rev B Condens Matter Mater Phys. 2005;72:085401.

36. Bogdanowicz R. Advancements in Diamond-Like Carbon Coatings. In: Handbook of Nanoceramic and Nanocomposite Coatings and Materials. Elsevier; 2015. Chapter 8, p. 183-205. https://doi.org/10.1016/B978-0-12-799947-0.00008-0.

37. Kumar N, Barve SA, Chopade SS, Kar R, Chand N, Dash $\mathrm{S}$, et al. Scratch resistance and tribological properties of $\mathrm{SiO} \mathrm{x}$ incorporated diamond-like carbon films deposited by r.f. plasma assisted chemical vapor deposition. Tribol Int. 2015;84:124-31. http://dx.doi.org/10.1016/j.triboint.2014.12.001.

38. Fei F, Wang Z, Chen Q, Liu Z, Sang L. Study of functional barrier layer on PVC by PECVD for migrations resistant. Surf. Coatings Technol. 2013;228(suppl 1):S61-6. http://dx.doi. org/10.1016/j.surfcoat.2012.08.040.

39. Vanhulsel A, Velasco F, Jacobs R, Eersels L, Havermans D, Roberts EW, et al. DLC solid lubricant coatings on ball bearings for space applications. Tribol Int. 2007;40(7):1186-94. http:// dx.doi.org/10.1016/j.triboint.2006.12.005. 